\title{
System Engineering Applied to Concept Design Optimization of Subsea Coolers
}

\author{
Arne Kristian Bye \\ Aker Subsea AS \\ arne.k.bye@akersolutions.com
}

\author{
Luca A. Piciaccia \\ Aker Subsea AS \\ luca.piciaccia@akersolutions.com
}

Copyright (C) 2013 by Arne K. Bye and Luca A Piciaccia. Published and used by INCOSE with permission.

\begin{abstract}
Subsea equipment must continuously evolve to meet the challenging conditions of the deep underwater environments. The optimization of coolers is a continuous process needed to remain competitive in this technology domain. This paper reports on the results of a project to study concept design optimization for the anti-surge cooler intended for a subsea compression station. The project followed the Aker Solutions project execution model, which begins with the creation of a concept of operations used to establish measures of performance, in addition to a valid requirements capture. The systems approach ensured that stakeholder needs were met, while identifying and refining parameters for the design. The refinement process, which resulted in a handful of design concepts, was evaluated through application of the AHP (Analytical Hierarchy Process) Decision Modeling Tool. Through this tool, the researcher arrived to a design concept recommendation, validated by stakeholders and sensitivity analysis.
\end{abstract}

\section{Introduction}

This paper reports on research conducted at Aker Subsea, a Norwegian supplier of subsea systems and part of Aker Solutions (AKSO). Subsea systems in the oil and gas industry are part of the technology for extraction of resources from reservoirs found below the ocean floor. The research targeted the optimization of passive subsea coolers in the emerging field of subsea compression and boosting technology. Subsea compression and boosting is an increase of hydrocarbon stream enthalpy by means of a compressor. The compressor thus enables the transport of well stream over longer distances and eliminates the need for additional existing fields to enter the critical flow region. Placing the compressor on the seabed instead of on a fixed platform or a floating production system increases the compressors utility by lowering the compressor inlet friction losses by significantly shortening the length of pipe between the fluid source and the compressor inlet. The need for subsea coolers is field and solution specific and the coolers may have various functions pending on where they are required. More specifically this research targeted the Anti-Surge Cooler applied in subsea compressor trains. The anti-surge circuit is needed on a compressor to mitigate the effect of rapid pressure variations across the compressor and to enable compressor anti-surge mapping.

An external customer asked AKSO to investigate if a proposed subsea cooler design could be more size efficient, which in turn triggered and motivated this cooler optimization research. The optimization of subsea coolers was approached using the company customized project execution model (PEM), which is loosely based on the SE vee-model [17]. Use of the PEM was augmented by Use Case Analysis (UCA) and Analytical Hierarchy Process (AHP). The top level view of PEM activities is depicted in figure 1. 


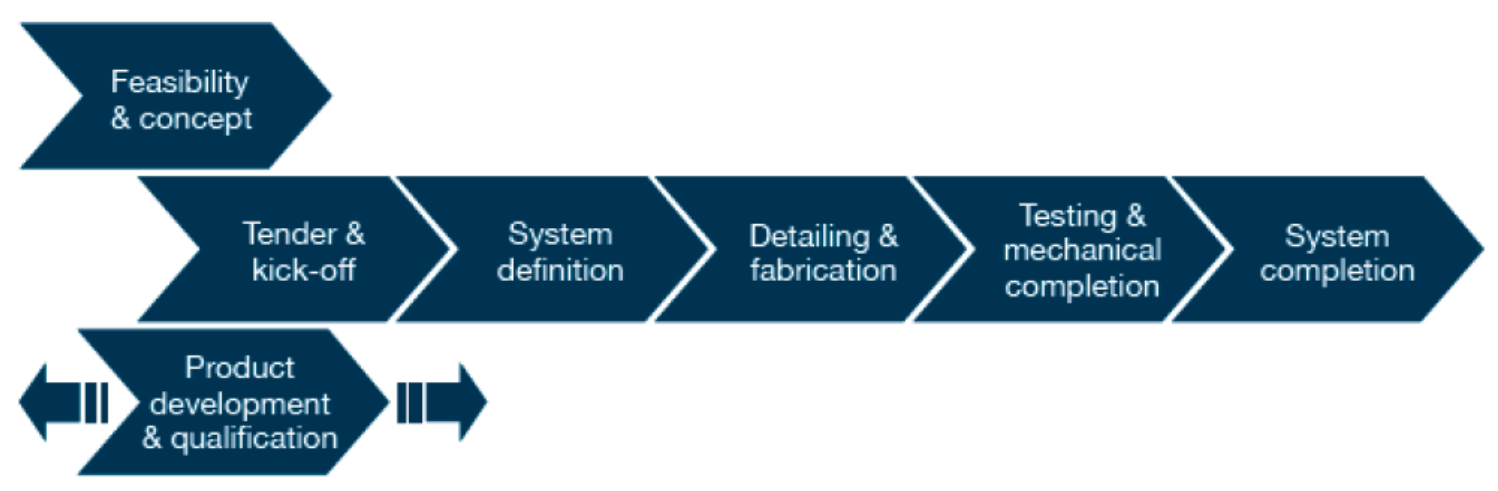

Figure 1. AKSO PEM top-level view

The process for feasibility \& concept development is shown in figure 2 , and provided the frame for this research.

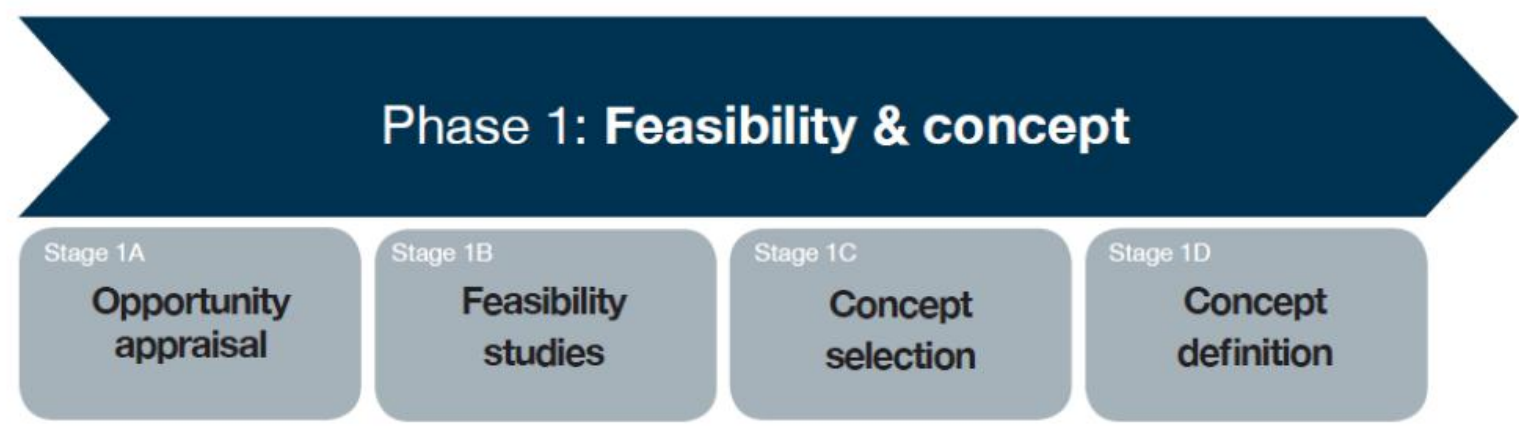

Figure 2. AKSO PEM feasibility and concept phase

Previous research [17] found that requirements definition and requirement analysis is not explicitly defined by the PEM. The requirement definition takes place as part of the contract agreement, which is negotiated separately from the PEM.

\section{Application of System Engineering}

The research activities followed fundamental SE principles [2, 4]. The research was based on re-using a component of the existing hardware. It was found essential for the trade-off study to evaluate the environmental conditions in which the cooler would operate. Evaluating environmental conditions ensured that requirements included constraints imposed by extreme subsea conditions. The research began with the identification of stakeholders, followed by stakeholder needs elicitation. The requirements elicited from stakeholders, and use case analysis were tabulated and classified as derived requirements. The customer requirements were taken directly from the customer specifications (functional requirements and basis for design) and classified as original requirements. The requirements capture formed a basis for the feasibility probing, and early validation and verification of the optimization engineering research. The AHP decision tool was applied to organize thinking and used as both a mathematical and visual tool to evaluate and communicate the pros and cons regarding the various cooler concepts.

Stakeholder Identification. An important step early in the systems engineering process is the identification of system stakeholders [4, 22]. They are represented as Entities in the research [2] and each of the Entities could be decomposed with finer granularity, as illustrated with internal 
\#2. The Materials Department had for example nine different contact points, to deal with different specialist topics and to mitigate the degree of subjectivity regarding assessments on welding and ease of assembly of the coolers. Once all relevant stakeholders had been identified, their needs were elicited through interviews.

The following Entity list was identified:

Entity List

- External: Customer

- Internal 1 Materials department

- Internal 2 Product Responsible departments including Compressor PRE (product responsible engineer) and Process Lead Internal 3 R\&D departments

- Internal 4 System Engineering Manager

- Internal 5 Sourcing and Logistics department

- Internal 6 CFD Department

Originating Requirements. The customer provided two documents, FDR (Functional Design Requirements) and BFD (Basis for Design). A high-level conceptual constraint derived from these user requirements was that the cooler shall be passive. This means that the cooler operates by transferring heat through natural convection to the surrounding seawater - yielding a robust design, as there are no moving parts. The general architecture includes a top header, cooler tubes, and a bottom header as depicted in figure 3 .

The gas to be cooled enters the top header inlet, is then distributed to the cooler tubes and cooled as it travels to the bottom header. A prototype of the compression system, including the subsea coolers had been built as a prototype for the purpose of testing and validating the operational capability of subsea compression. The prototype design was used mainly to validate functional performance of the subsea coolers, and was also used to calibrate the thermal modeling tools applied in the design process. The optimization process took into account the "as is" state of the passive coolers, including interfaces with other systems. This provided a deep background understanding of the existing solution and the supporting technology, typical of research conducted as middle-out engineering [1].

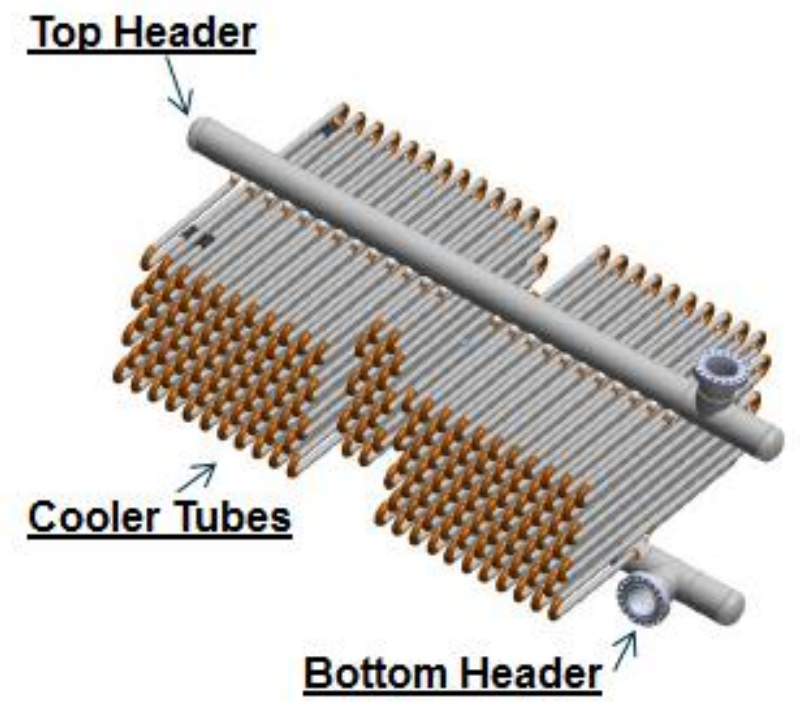

Figure 3. Generic configuration of passive cooler

Use Case Analysis. Interviews were conducted with Compressor PRE (product responsible engineer), Process Lead and CFD (Computational Fluid Dynamics) Lead from which it was 
derived that for more than $99 \%$ of the coolers' lifetime the Anti-Surge (AS) Cooler system would not be actively used. A significantly large part of the coolers life would be in a standby mode as depicted below in Figure 4, Use Case 1. The use cases identified as relevant during the Anti-Surge coolers operational life were Anti-Surge Circulation modes and surge mapping [5]. Both use cases are rare occurrences, with mapping of the compressor only being performed once for each compressor bundle. What this actually meant is that the internal environment that the cooler was exposed to is not the same as the regular pipe flow line. Most of the cooler's lifetime would be to an internal stagnant exposure to hydrocarbons - this meant that the cooler internals could be considered as nominally dry for corrosion analysis purposes.

Anti-Surge scenarios could occur if the compressor is operating and there is insufficient gas flow at the compressor inlet. This may happen during unplanned well shut down. In such a use-case, the Anti-surge valve opens and the MPV (main production valve) closes to protect the compressor from surging and eventually failing with serious consequence. The produced gas circulates in a closed loop as illustrated in use case $2 \& 3$ in figure 4.

Surge mapping is a scenario where the compressor runs at various speeds to map surge lines. If the compressor reaches these surge lines it could break down, hence this is a critical operation. During the AS mapping, the gas flows through the same loops as in the Anti-Surge cases illustrated in use case $2 \& 3$ figure 4 . The Anti- Surge mapping use-case is planned to occur every time the internals of the compressor are modified, which is planned to happen approx. every $5^{\text {th }}$ year to re-set the process safeguards trip levels.

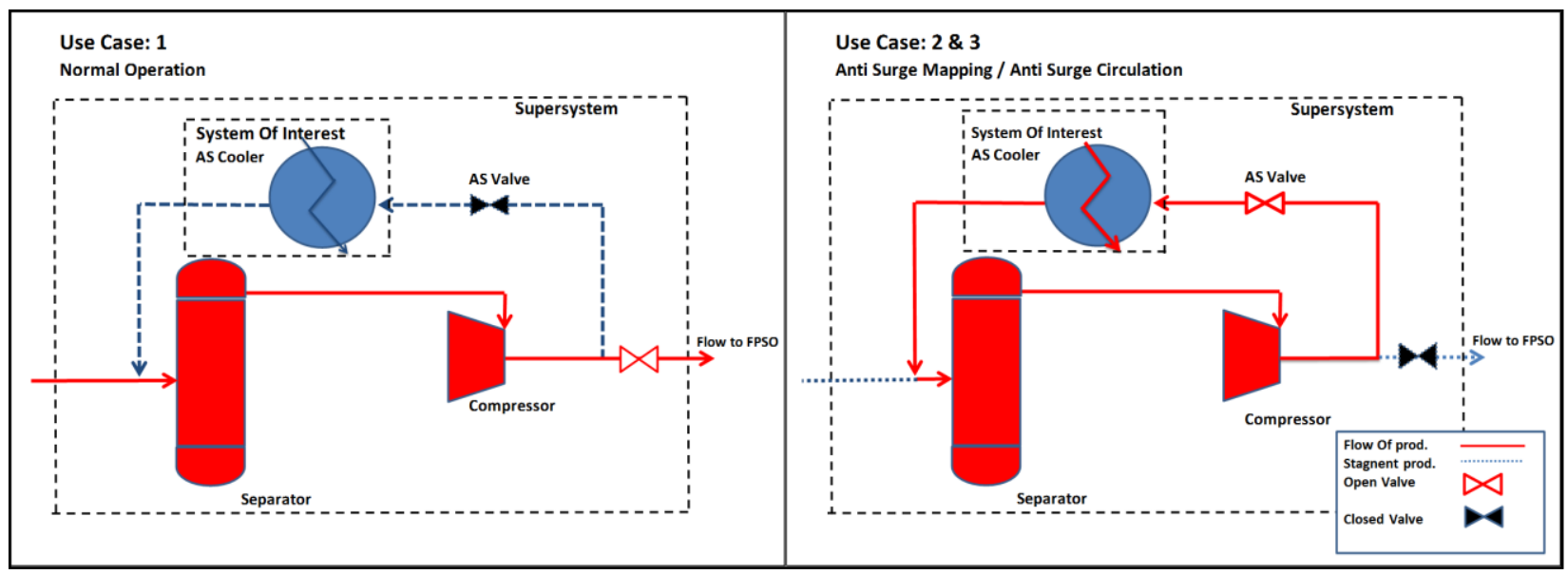

Figure 4. Process Diagrams for use cases 1-3

Using the results of the UCA two significant findings were made:

1. The cooler internals could be considered nominally dry, which in turn allows for the application of lower alloy steels (if complimented with an assessment on internal corrosion analysis))

2. Larger Inner Diameters in cooler tubes were considered favourable for Hydrate mitigation, revealing that an increase in tube dimensions yielded an operational robustness.

An increase in tube outer diameter was on the one hand beneficial for mitigating hydrates clogging tubes, and on the other hand increased the size of the cooler. The UCA broadened the research picture, namely to investigate if a cooler design concept could have larger tube dimensions and still meet the space constraints of the current design. This prompted an evaluation of dimensional constraints in the feasibility studies phase. The research question 
was constructed as "How sensitive is the cooling tubes thermal conductivity to the coolers overall compactness?"

Requirements Capture. At the conclusion of the use case analysis a complete set of requirements, both originating and derived, were tabularized. These are listed in Appendix A and formed a design basis for the feasibility study.

\section{Feasibility Study}

The process loop prescribing the activities that support the AKSO feasibility study stage is depicted in figure 5. The PEM is represented as a linear process, suggesting a logical sequence in which engineering activities should occur. The feasibility study is an engineering activity that can often appear chaotic and in reality is iterative and time consuming.

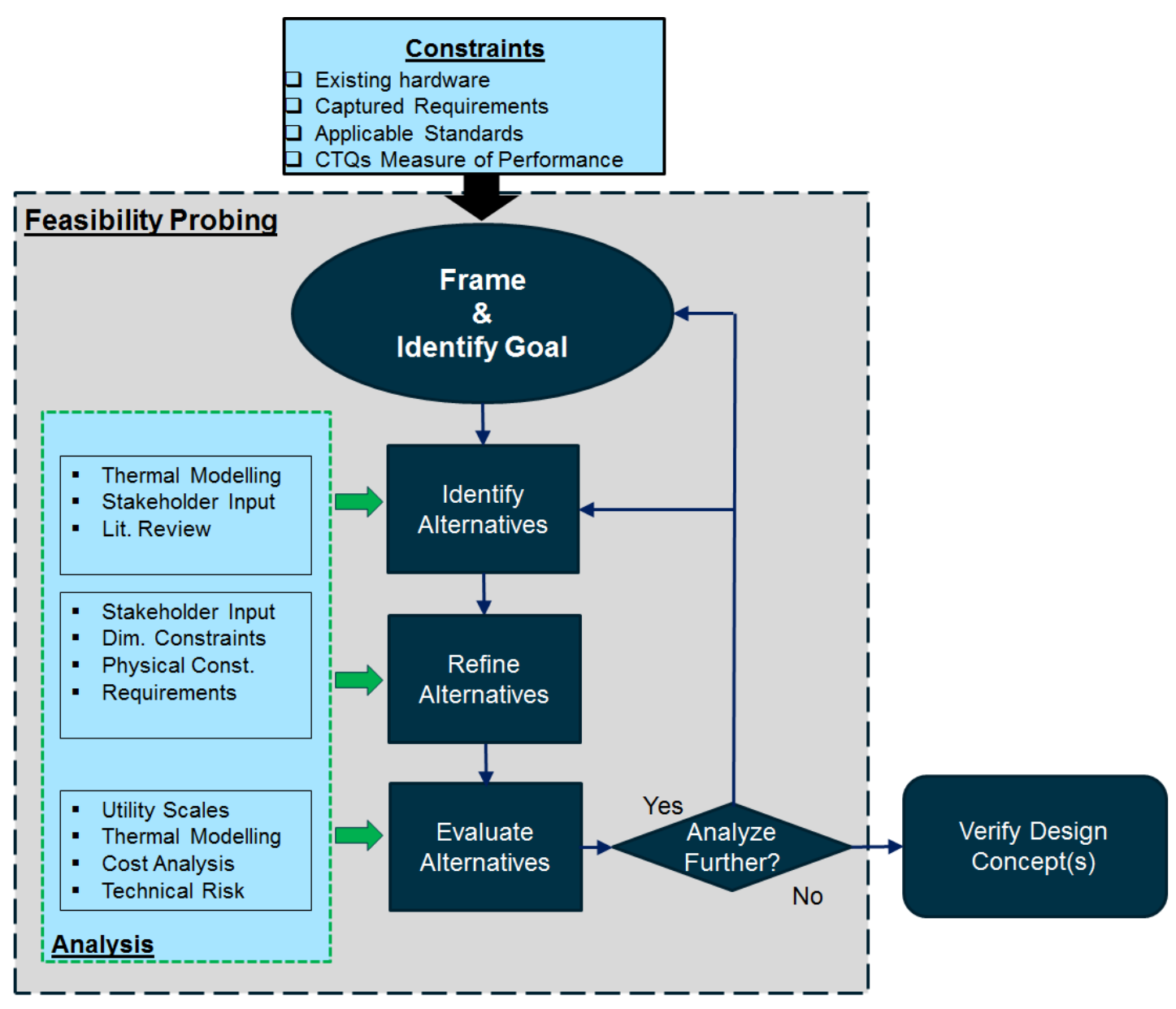

Figure 5. Feasibility Studies per AKSO PEM

Identify Alternatives. The first critical step was to establish a reasonable range of potential alternatives. The identification of alternatives is a time consuming process of researching literature, interviewing and brainstorming with stakeholders to get a better understanding of the impact alternatives have on the research question.

The thermal modelling tool had validated that an increase in cooler tubes thermal conductivity could reduce the coolers size up to 25\% - See appendix B, Thermal Modelling. This prompted the research to find alternative tube materials with higher thermal conductivity. An additional 
motivation was that the initially proposed material selection did not fit into the Process Module with larger tube size.

A literature review and several interviews in the materials department had resulted in 13 potential tube materials [8] [9] [10].

Refine Alternatives. Stakeholders provided important information as input to refine the alternative solutions. The needs elicited from stakeholders, the UCA, and the resulting requirements capture had contributed to a logical refinement process. The captured constraints had led to the favouring of larger tube dimensions; however the initially proposed design concept with small tube dimension was used for bench marking and for the purpose of representing a "mature" concept (used for previous project). The determination of coating was set as a default pending on the materials alloying level (requirements capture). The tube wall thickness was determined as a function of material specified minimum yield strength de-rated at design temperature, with the closest highest thickness determined by industry standards. The materials appropriateness was at first stage refined as a function of strength - and the alternatives that had sufficient strength were run through a constructability assessment. One of the key drivers in the assessment of constructability was evaluating if the alternative had a subsea track record and if the alternative was prone to HISC (Hydrogen Induced Stress Cracking). HISC is a failure mode in which hydrogen diffuses into the material and decreases the materials toughness, potentially leading to its cracking [14]. All proposed concepts had to go through refinement by materials specialists considering operational threats; HISC susceptibility, internal corrosion, galvanic effects due to interfacing systems, and proper external corrosion protection. Some of these elements formed as part of the "must haves" in the concept evaluation, and therefore formed part of the relevant information in the screening process. The refinement process resulted in only five of the original 13 potential design concepts continuing in the process to be further evaluated.

Evaluate alternatives. The PEM guidelines used in AKSO do not stipulate a formalized method for the evaluation of alternative concepts. A Multi Criteria Decision Model (MCDM) approach was considered appropriate for this evaluation because they present a systematic approach, to process information using the concept of hierarchical structure analysis to help decision makers to make good decisions in uncertain environments. Studies have shown that MCDM tools have been effective for technical concept selection decisions [5, 7] However, there are several MCDM methods from which to choose.

This research considered using Kepner-Tregoe Process, and a pugh matrix [4, 11], but found the criteria weights to be difficult to pinpoint, even when stakeholders could aid in assessing weights. The internal diameter of the tubes was considered to have significant design impact but quantifying the impact was difficult. The Weight Sum Model (WSM) was also considered, however WSM should be used only when the decision criteria can be expressed in identical units of measure (e.g. only dollars, or only seconds etc.) [13]. Concern over the use of weights that were not validated was mitigated by approaching the problem with AHP. AHP uses a simple mathematical logarithm for determining weights, this way the weights do not appear from "thin air". In addition, the weights are validated through sensitivity analysis and screened through stakeholders. Finally, AHP has a famous record of accomplishment in aiding in the solving of complex decisions [11] and is considered by many as the most reliable MCDM tool [18]. These arguments were the basis for selecting AHP as a final tool in the design concept evaluation. 
The CTQs (Critical to Quality) used as the main criteria in the decision model were identified as maximize constructability, maximize operational robustness, minimize cost and minimize risk. In the requirement elicitation phase, the ranking of requirements and the tradeoff analysis on the conflicting ones led to a shortlist of four main design parameters related to the cooling tubes:

1. Material selection

2. Coating technology, if any

3. Oater diameter (OD)

4. Wall thickness

The joint settings of the above parameters are what this research refers to as design concepts. The reason for not including other variables such as dimensions of the header, number of tubes in headers, horizontal tube spacing, vertical tube spacing and the like was grounded in that the cooler was to be designed as compactly as possible, thus evoking dimensional constraints on the design once the four parameters were selected. The Header would for example be saturated with tubes, the height would be constrained, and the number of tube stacking would be determined by the diameter of the bends and the space in which the cooler had allocated, according to best practices based on previous experience.

Each of the above parameters were approached individually in the feasibility probing process, but were addressed jointly in the later evaluation of design concepts. The reason was that it was easier to study parameters separately, and then jointly as design concepts when they represented different "emphasis" in the quality attributes. For example, a design concept could be highly cost effective, but not robust. Another design concept could be cost effective and robust however, associated with high risk.

Verify Design Concepts. Due to constraints in time, and financial resources this research did not perform detailed verification of design changes, i.e. move into the next phases of the PEM. Therefore, the research could not verify the thermal dynamic impact on natural convection created by the steady state heat up of seawater surrounding the coolers. The verification effort put into the research was through stakeholder interviews and numerical calculation done by hand, spreadsheets and using the AKSO developed thermal modeling tool.

\section{AHP Decision Model \& Results}

Introduction. The AHP method, developed by Tom Saaty, is a decision support tool that can be used to solve complex decision problems. AHP uses a multi-level hierarchical structure of objectives, criteria, sub-criteria and alternatives or concepts in this research. The pertinent data are derived using a set of pairwise comparisons. These comparisons are used to obtain the weights of importance of the decision criteria, and the relative performance measures of the alternatives in terms of each individual decision criterion $[11,18]$.

In this research AHP was applied to organize the thinking and evaluate the refined design concepts. The AHP method was used directly when handling tangible criteria. An evaluation tool was created by the researcher, based on the literature, using Microsoft Excel ${ }^{\mathrm{TM}}$ software. But the tool was modified so that it processed intangible information such as Risk and Opportunity in an "information box". This way the tool became an efficient way to conduct quantitative evaluations that could be compared side by side and at the same time provide valuable qualitative information about risk and opportunity, which undoubtedly influence the decision making process. The hybrid AHP method was able to process the information elicited from various stakeholders and literature review. The compact nature of the presentation meant 
that the pros and cons of each option were easily and effectively communicated to relevant stakeholders. Figure 6 contains the eventual AHP Matrix upon which the following discussion is based.

Identification of Criteria. The main criteria used in the AHP were the CTQs derived from stakeholder needs elicitation. These criteria were further decomposed which was a necessary mean to mitigate subjectivity and to effectively measure design concepts. Cost was a complex assessment, and was measured in percent relative cost of material and assumed manufacturing cost (based cost of materials and previous data on cost of manufacturing). But how should we measure constructability? Constructability was decomposed into 3 sub-criteria; number of welds (which varied greatly), the materials ease of weldability, and ease of coating application.

The systems robustness was measured in three sub- criteria. The most important of these was to maximize inner diameter because a larger inner diameter mitigated the risk of the tubes clogging due to the formation of hydrates. The other two were "fitting the required amount of anodes" and "second barrier corrosion protection". If a system could not fit the required amount of anodes, its lifetime had to be de-rated, thus not meeting the 25 -year lifetime requirement. The second barrier corrosion was related to $\mathrm{CP}$ (Cathodic Protection) failure. Should the CP system fail to protect areas of the cooler the cooler would have to rely on its secondary protection; i.e. either the tubes passive protective film (pending on alloy), or the coating. Anodic coatings offered added robustness due to its combination of coating barrier and sacrificial properties (pending on substrate selection).

Cost did not require decomposing, and was measured as percentage reference to the budgeted cost of the initial design concept. The analysis for determining cost was based on real time gathered cost on required length of tubes combined with the budgetary cost of manufacturing the design, elicited based on previous projects and todays cost material cost.

Some design concepts intangibles were not used in the AHP numerical evaluation. Instead, they identified in a risk/opportunity box were the risk level was highlighted with color codes indicating their criticality. This way the decision maker could make their own assessment on how much risk they were willing to take - and apart from the concept's weldability, the design concept's score would be based on tangible indicators.

Global weights. The weighting of each criterion had been initially carried out by the researcher, and later reviewed by stakeholders. The weighting of each criterion was derived through side by side comparison, e.g. is weldability more important than cost? But before evaluating the weights it was found important to determine the consistency of pair-wise comparison. This research found it crucial to have a valid understanding of the importance of a given criterion relative to what it was compared with - should the number of welds weigh more than the concept's weldability?

A thorough refinement process had resulted in a select few feasible design concepts. Because the feasibility of these concepts were each so high, to truly reflect an optimized solution it was important that this was taken into account in the side by side comparison. Great care was taken in determining the weights, the scaling and scoring in each criterion. For example, none of the considered concepts required PWHT (post weld head treatment), and were considered to have an equal degree of repeatability. If all concepts were considered equally weldable, there was no point having weldability as a measure for differentiating the concepts. The concepts had low variation with regards to weldability, but a variation did exist. And when taking the low variation into account it was natural that the weight of weldability was lower than the number 
of welds criterion which had high variation. This finding was also in line with previous research, arguing that weights depend on both importance and variation [19]. The weights were therefore determined as a function of variation and weight.

All the design concepts compared in the AHP tool were of high technical standard, adhering to the identified requirements - cost was therefore weighted as one of the top two most important criteria.

Rating. The rating that every concept received on each criterion was based on a 6 point scale, ranging from very low 0.01 to very high 0.41 . These values and the values in between were established following the AHP side by side technique. The assigned values were based on how they scored compared to 5 competing concepts, their variety of their performance and the utility scales. In some cases utility scales were very important. For example; two design concepts requiring respectively 5 and 51 sacrificial anodes yielded a score close to each other because the research had found that the cooler frame was approximately saturated at 54 sacrificial anodes. This means that there was no issue fitting the required anodes and the cost and time of assembly with the two concepts were considered negligible compared to the big picture. The high number of anodes could however affect operational integrity from a risk perspective; e.g. higher hydrogen evolution and the formation dynamics of calcareous deposits (effecting heat transfer). But these elements were included in the risk assessment to highlight it in the decision making process. If a concept exceeded 54 anodes the score reflected this by a "very low" score 0.01 . If the number was below or equal to 54 the score would range from a "Very High" 0.41 to "Medium Plus" 0.28 - reflecting a consistent score that was in line with this contrast.

Another example was the difference between concepts where tube inner diameter was "low" and "high". The risk in which the tubes could clog due to hydrates in equal environments followed an exponential curve where the tubes would clog in 5 hours for the low tube ID case and 5 days for the high ID case - giving an indicator of the sensitivity of the inner diameter with regards to operational stability.

The rating each concept had on the criterion attempted to follow a consistent approach as described above.

Sensitivity Analysis. Determining validated weights using AHP can be difficult. Consequently, the possibility exists that AHP does not truly representing the numerical "winner" $[13,18]$. As part of the AHP Method, a sensitivity analysis was performed. The analysis helps the AHP user to better understand why alternatives are chosen over other alternatives and helps the user reflect if the results are valid.

The analysis began with studying the criteria's high-level weights (Constructability, Robustness and Cost). It was conducted through simply altering weights determining what was most important. All "views" were easily studied in a semi-automatic spreadsheet table. The results from this experiment uncovered that design concept 1 was in each case the numerical loser and that design concept 5 was in each case the winner by an average of respectively $50 \%$ and $25 \%$ relative to the next closest numerical concept. A tight numerical race between design concept 2, 3 and 4 was observed. A microanalysis assessing the importance of the sub-criteria was therefore initiated to study further impact on sensitivity. The microanalysis was studied in the same approach as the global criteria (e.g. by changing importance level and rank of sub criteria). However, the microanalysis had to be studied with some "locked" views on high level weights - Two "views" were selected for comparison. View 1 consisted of Robustness being slightly more important than Cost, and Cost being slightly more important than Constructability. View 2; Cost and Robustness being equally important, and slightly more 
important than Constructability. In view 1, design concept 4 was always the numerical winner (behind design concept 5), scoring on average 5-10\% higher than design Concept 2 and 3. In view 2 , when emphasis was made on cost the design concept 2 and 3 scored numerically higher. When mitigating hydrates was considered the most important, then Concept 3 was the winner. When $2^{\text {nd }}$ barrier and anodes was most important in this view, design Concept 2 was the numerical winner.

The reason for selecting the two views was suggested by what key stakeholders considered as interesting. Constructability was not deemed more important in any case because all the design concepts were low variety in that respect. All in all - stakeholders had reviewed the table with requirements derived from use case analysis in mind, thus concluding that the AHP matrix reflected the stakeholder needs. The end result is depicted in Figure 6 - AHP Decision Matrix.

Summary. Thinking about the problem using the AHP method helped the researchers organize their thoughts and locate all the information elicited and researched in one precise artifact. It was furthermore interesting to learn that the starting point initiating the research was motivated by the intent of minimizing the cooler size, and cost, but ended with validating the need for increasing the size of the cooler (larger tubes, mitigating hydrates), and that a larger cooler in weight and volume could even be more cost-effective.

This discussion also illustrates the use of a hybrid tool that instead of quantifying risk and opportunity in the decision tool, visualized them in information boxes listing the risk and opportunities for the various concepts and coloring it based on the probability / severity associated with them. 


\section{Design Concept}

\begin{tabular}{|c|c|c|c|c|c|c|c|c|c|c|c|c|c|c|c|c|}
\hline \multirow{2}{*}{\multicolumn{2}{|c|}{ Design Concepts }} & \multirow{2}{*}{\multicolumn{3}{|c|}{ HCRA - Uncoated - S. Tube ID - MW }} & \multicolumn{3}{|c|}{2} & \multicolumn{3}{|c|}{3} & \multicolumn{3}{|c|}{4} & \multicolumn{3}{|c|}{5} \\
\hline & & & & & \multicolumn{3}{|c|}{ M CRA - Anodic C. - M. Tube ID - MW } & \multicolumn{3}{|c|}{ H CRA - Uncoated - L. Tube ID - TW } & \multicolumn{3}{|c|}{ M CRA - Anodic C. - L Tube ID - MW } & \multicolumn{3}{|c|}{ LAS - Anodic C. - L. Tube ID - HW } \\
\hline SubCriteria & Global Weight & \begin{tabular}{|c|} 
offer \\
-
\end{tabular} & Rating & Score & Offer & Rating & Score & Offer & Rating & Score & Offer & Rating & Score & Offer & Rating & Score \\
\hline \begin{tabular}{|l|} 
Max. Inner Diameter (min. Hyd plugs) \\
\end{tabular} & 0,29 & Low ID & 0,01 & 0,0029 & Medium ID & 0,2 & 0,0588 & High ID & 0,41 & 0,1205 & High ID & 0,41 & 0,1205 & Medium +1D & 0,28 & 0,0823 \\
\hline Max 2nd Barrier Corrosion Protection & 0,15 & HCRA & 0,2 & 0,0294 & MCRA+Anodic C. & 0,41 & 0,0602 & HCRA & 0,2 & 0,0294 & MCRA+Anodic C. & 0,41 & 0,0602 & LAS + Anodic C. & 0,41 & 0,0602 \\
\hline Min. Anode needs(weight/F. Current) & 0,14 & $51 \times A n(5000 \mathrm{~kg} / 70 \mathrm{~A})$ & 0,28 & 0,0389 & $4 \times A n(392 \mathrm{~kg} / 3 \mathrm{~A})$ & 0,41 & 0,0569 & $57 \times A n(5600 \mathrm{~kg} / 84 \mathrm{~A})$ & 0,1 & 0,0139 & $6 \times A n(588 \mathrm{~kg} / 5,2 \mathrm{~A})$ & 0,41 & 0,0569 & $5 \times \mathrm{AA}(490 \mathrm{~kg} / 4,1 \mathrm{~A})$ & 0,41 & 0,0569 \\
\hline Min. no. Welds & 0,09 & 1500 (bended) & 0,1 & 0,0086 & 1200 (fittings) & 0,2 & 0,0171 & 960 (fittings) & 0,28 & 0,0240 & 960 (fittings) & 0,28 & 0,0240 & 480 (bended) & 0,41 & 0,0351 \\
\hline Max. Weldability & 0,03 & Good & 0,31 & 0,0089 & Good & 0,31 & 0,0089 & Medium & 0,2 & 0,0057 & Good & 0,31 & 0,0089 & Very Good & 0,41 & 0,0117 \\
\hline Max Coatability & 0,03 & Uncoated & 0,41 & 0,0117 & Anodic C. & 0,1 & 0,0029 & Uncoated & 0,41 & 0,0117 & Anodic C. & 0,2 & 0,0057 & Anodic C. & 0,2 & 0,0057 \\
\hline Min. Cost (Relative to initial Concept) & 0,29 & $100 \%$ & 0,1 & 0,0286 & $89 \%$ & 0,28 & 0,0800 & $88 \%$ & 0,28 & 0,0800 & $98 \%$ & 0,1 & 0,0286 & $81 \%$ & 0,41 & 0,1171 \\
\hline Identified Risk & & $\begin{array}{l}\frac{\text { RED }}{\text { - Hydrates Cloging Tub }} \\
\text { - High Cost } \\
\text {-yydrogen Evolution a } \\
\text { Buildup }\end{array}$ & $d C P$ & ed Calc. & $\begin{array}{l}\text { GREEN } \\
\text { - Anodic C. TQP } \\
\text { - New Manufacturing } \\
\text { (HIP) }\end{array}$ & Process & aders & $\begin{array}{l}\text { Yellow } \\
\text { - New Manufacturing Pr } \\
\text { - Hydrogen Evolution an } \\
\text { Buildup } \\
\text { - Unlikely to Fit All Anod }\end{array}$ & $\begin{array}{l}\text { cess Heac } \\
\text { ICP Induc } \\
\text { s }\end{array}$ & ris (HIP) & \begin{tabular}{|l|} 
GREEN \\
-Anodic C. TQPP \\
- New Manufacturing
\end{tabular} & Process $\mathrm{HE}$ & ders (HIP) & $\begin{array}{l}\frac{\text { RED }}{\text { - Anodic C. TQP }} \\
\text {-Internal Corr. Analy } \\
\text { - Uncertainty Constr } \\
\text { input/ banana effect }\end{array}$ & ion of he & ers (heat \\
\hline Opportunities & & $\begin{array}{l}\text { - Success With Materia } \\
\text { Construction process } \\
\text { - Modeled Design, part }\end{array}$ & $\begin{array}{l}\text { Selection } \\
\text { verified }\end{array}$ & & \begin{tabular}{|l} 
- Advanatage to hav \\
quallified for cooler \\
- Cost Effective
\end{tabular} & $\begin{array}{l}\text { anodic co } \\
\text { chnnology }\end{array}$ & tings & $\begin{array}{l}\text { - Advanatage to have an } \\
\text { for cooler technology pc } \\
\text { - Cost Effective }\end{array}$ & $\begin{array}{l}\text { dic coatin } \\
\text { tifolio }\end{array}$ & s quallified & \begin{tabular}{|l} 
- Advanatage to incluc \\
for cooler technology
\end{tabular} & $\begin{array}{l}\text { le anodic } \\
\text { portifolio }\end{array}$ & atings in - & $\begin{array}{l}\text { - Advanatage to have } \\
\text { quallified for cooler t } \\
\text { - Highly cost Effectiv } \\
\text { - Innovative and com }\end{array}$ & $\begin{array}{l}\text { todic coa } \\
\text { nnology } \\
\text { tative de }\end{array}$ & tifolio \\
\hline Total Score & & 12 & & & & 35 & & 28 & & & 3 & 05 & & -13 & 9' & \\
\hline
\end{tabular}

Red: High Risk

Yellow: Medium Risk

'Green: Low Risk _ _

\section{Figure 6, AHP Matrix}

* See appendix A Table 2 for abbreviations. 


\section{Discussion}

SE Application. The needs elicitation and UCA identified high level criteria against which the goodness of potential design concepts could be evaluated. The UCA revealed the possibility for an alternative material selection, which could yield a serious advantage compared to competing solutions. Another important finding was the identification of hydrate formation as an operational threat, which was not considered in the original requirement capture. Finally, the UCA suggested the cooler needed larger tubes, which was in direct conflict with the original problem statement to minimize size. $45 \%$ of the captured requirements were derived from stakeholder needs elicitation and the UCA and suggest that SE plays an important role, also in middle out engineering practices.

Generic reusability. The many viewpoints collected during stakeholder needs elicitation and UCA may often suggest different means of optimizing and designing subsea passive coolers. As requirements continuously shift with changing situations, projects, system solutions, environment, and stakeholders, so too must the options and design concepts be improved continuously. This is true for this research, on a generic level and also in line with literature on the topic [20]. Passive Subsea Coolers have to be tailored to the needs of specific field solutions, and applying this approach may reduce the capital expenditure (CAPEX) and Operational Expenditure (OPEX) through a reduction in cost related to constructability and unforeseen maintenance intervals, at the same time increasing the operational reliability thus mitigating equipment-related down time for the field. Therefore, this research approach should be considered applicable for subsea coolers on a generic level.

Multi Criteria Decision Model. Because such a decision model is subjective, it often yields inconsistencies that are difficult to eliminate even after repeating the process several times. In retrospect selecting the pugh method might have been just as valid an approach as the AHP. Both methods may be used to organize thinking and communicate the pros/cons of design concepts. An advantage with applying the pugh matrix is that it is quicker to perform and easier to understand. The extra time spent performing AHP however can be used to perform simple statistical tests to check for consistency in the evaluation of the weighting coefficients and the individual utilities which aid the user understand why a concept is preferred [21].

There is sufficient evidence from previous research [18] to suggest that recommendations derived through AHP should not be taken literally. The closer the final values are with each other, the more careful the user should be. This is true with any MCDM method [18]. Previous research [18] also found that MCDM methods should be used as decision support tools and not as the means for deriving the final answer.

\section{Conclusion and Future research}

All decisions may be considered somewhat subjective [11], this research has sought objectivity using the Aker Solutions PEM approach combined with needs elicitation, UCA, concept feasibility studies and the AHP. The conclusion and output of this research is as follows:

- This research found that stakeholder needs elicitation and UCA are an effective approach for creating design optimization space and capturing new requirements.

- To organize thoughts, determine relative weights of criteria, to easily communicate risk/opportunity, pros and cons and to aid the user understand why a concept is preferred; the AHP is the preferred MCDM method.

- A hybrid AHP decision tool provided an efficient artefact that can support the reasoning of the decision makers. 
This research supported the conclusion to pursue design concept nr 4: Low Tube ID - M CRA - Anodic Coating - Medium Walled solution yielding a robust design concept mitigating clogging of tubes, and yielding high corrosion resistance. The reason for not recommending design concept winner no. 5 is due to the identified risks and uncertainty associated with that option. If the decision makers believe that cost is a major driver for winning the project - it is recommended to further investigate and verify application of CS solution by the means of establishing a thorough corrosion analysis. In addition, it is recommended to engage in a design verification process addressing how headers may be constructed of CS.

This research did not perform detailed verification of the recommended design concept. If the proposed concept is to be pursued a detailed verification effort on the proposed design concept is required. Typical verification effort includes 3D- Modelling, and verifying successful integration in the Process Module; verifying thermal performance through CFD Simulations, where natural convection may be simulated and taking into account chimney effect, pipe stacking and the like; and conducting a successful Technical Qualification Programme on anodic coatings.

For future generation passive subsea coolers optimization the PEM and the design concept Optimization Process (figure 5) may be applicable. The effect of integrating technology such as coating, and material selection may yield further optimization of passive coolers.

\section{Acknowledgements}

This work was executed as part of the systems engineering industry master's program at the Buskerud University College under the supervision of Professor Alberto Sols. The researcher thanks the many internal Aker Solutions stakeholders for their cooperation, his Industry

Supervisor and co-author, Chief Systems Engineer Luca Piciaccia, Industry Supervisor Are M. Synnes and CFD Manager Henrik Alfredsson. Thanks also to Associate Professor Cecilia Haskins and five anonymous reviewers for suggestions for this paper.

\section{References}

[1] Long, D. and Scott, Z. (2011). "A Primer for Model-Based Systems Engineering" 2nd ed. Blacksburg VA: Vitech Corporation.

[2] Oliver, David W. And Kelliher, Timothy P And Keegan Jr, James G. 1997. "Engineering Complex Systems with Models and Objects"

[3] Haskins, C., ed. 2010. Systems Engineering Handbook: A guide for System Life Cycle Processes and Activities. Version 3.2 Revised by M. Krueger, D. Walden, and R. D. Hamelin. San Diago, CA (US): INCOSE.

[4] Barrese, Anthony 2010. SDOE 625 - "Fundamentals of Systems Engineering", Stevens Institute of Technology.

[5] Ondurus, Jan and Bui, Tung, And Pigneur Yves. "A multi-actor, multi criteria approach for technology selection when designing mobile information systems"

[6] Gulbrandsen, Egil and Morard, Jean Herve 1998, "Why does Glycol Inhibit CO2 Corrosion?", NACE 98221

[7] Honkala, Sauli and Hämäläinen, Matti and Salonen, Mikko., 2007, “Comparison of four existing concept selection methods". 
[8] Pugh, S. J. And Hewitt, G. F. And Müller-Steinhagen, H. 2005. 'Fouling During the Use of Seawater as Coolant - the Development of a User Guide“"

[9] ASME II part D Boiler \& Pressure Vessel Code, 2008. "Properties (Metric) Materials"

[10] Lunde, Liv And Johnsen Roy, 1986. "Sjøvannsbestandige materialer Kunskapsoverføring fra kjernekraft til Offshoreindustrien"

[11] Whalen, James 2012. SYS 660 - "Decision and Risk Analysis", Stevens Institute of Technology.

[12] Bai, Yong and Bai Qiang, 2005. "Subsea Pipelines and Risers"

[13] Triantaphyllou, Evangelos 1997, “A Sensitivity analysis approach for some deterministic multi-criteria decision making methods", Decision Sciences, Vol. 28. No. 1, pp. 151 194.

[14] DNV Recommended Practice, 2010. "Cathodic Protection Design"

[15] Springer, 2006 2nd edition "VDI Heat Atlas"

[16] ASME B31.8, 2007 "Gas Transmission and Distribution Piping Systems"

[17] Mjånes, Jan Ove and Haskins, Cecilia and Piciaccia, Luca A., 2012, "Closing the loop for lifecycle product management in Norwegian subsea systems." Proceedings of the 23rd annual international symposium of the International Council on Systems Engineering.

[18] Triantaphyllou, E. And Mann S. H. 1995. "Using the Analytic Hierarchy Process for Decision Making in Engineering Applications: Some Challenges"

[19] Parnell G. S. And Trainor T. E. 2009. "Using the Swing Marix to Weight Multible Objectives"

[20] Haskins, Cecilia. 2008. "System engineering analyzed, synthesized, and applied to sustainable industrial park development"

[21] Ncube C. and Maiden N. "PORE: Procurement-Oriented Requirements Engineering Method for the Component-Based System Engineering Development Paradig

\section{Biography}

Arne Kristian Bye is a Materials Engineer at Aker Solutions. He has 3 years' experience from the Norwegian Oil \& Gas industry. He holds a bachelor degree in Mechanical \& Materials Engineering from Sør- Trøndelag University College (HiST). This paper is the result of a research done for his Master's degree in Systems Engineering at Buskerud University College ( $\mathrm{HiBu})$

Luca Abele Piciaccia developed his 25+ years systems engineering career in the Subsea Oil Industry at Major Oil Companies and leading EPC contractors, where he held several positions as Engineering Manager and Commissioning Responsible before becoming Chief Engineer Subsea Systems Engineering for Major Subsea Projects. His education includes Nuclear Engineering at the Politechnic University in Milano, BSc in Engineering Management at CCU and an MBA in Technology Management from Chiefly Business School in Australia. Luca has served 2 terms as president of the Norwegian INCOSE chapter. 


\section{Appendix A - Requirements Capture Table}

Table 1: Requirements, class, source and handling method

\begin{tabular}{|c|c|c|c|}
\hline Requirement & Classification & Source & Handling Method \\
\hline Coolers Shall be Passive. & Original Req. & $\begin{array}{l}\text { Customer, } \\
\text { BFD }\end{array}$ & Passive Cooler Design \\
\hline $\begin{array}{l}\text { The AS Cooler Lifetime shall be } 25 \\
\text { years. }\end{array}$ & Original Req. & $\begin{array}{l}\text { Customer, } \\
\text { BFD }\end{array}$ & $\begin{array}{l}\text { Effect on Anode } \\
\text { demands. Other } \\
\text { verification activities } \\
\text { such as fatigue. Not } \\
\text { addressed in this } \\
\text { research. }\end{array}$ \\
\hline Design Pressure is 255 Bar. & Original Req. & $\begin{array}{l}\text { Customer, } \\
\text { BFD }\end{array}$ & $\begin{array}{l}\text { Verified in Strength } \\
\text { Check. }\end{array}$ \\
\hline The Water depth is $880 \mathrm{~m}$. & Info. & $\begin{array}{l}\text { Customer, } \\
\text { BFD }\end{array}$ & $\begin{array}{l}\text { Verified in Strength } \\
\text { Check. }\end{array}$ \\
\hline $\begin{array}{l}\text { Design Temperature is from range: } \\
-30{ }^{\circ} \mathrm{C}-140^{\circ} \mathrm{C}(\min / \max ) .\end{array}$ & Original Req. & $\begin{array}{l}\text { Customer, } \\
\text { BFD }\end{array}$ & $\begin{array}{l}\text { Materials de-rated } \\
\text { according to max. } \\
\text { temperature. Verified } \\
\text { in Strength Check. }\end{array}$ \\
\hline $\begin{array}{l}\text { No Marine Growth is expected at the } \\
\text { subsea location. }\end{array}$ & Info & $\begin{array}{l}\text { Customer, } \\
\text { BFD }\end{array}$ & \\
\hline $\begin{array}{l}\text { All materials in contact with well } \\
\text { fluids shall be manufactured in a } \\
\text { suitable CRA or } \\
\text { Internally clad carbon steel. } \\
\text { Exceptions to this may be considered } \\
\text { for parts of the station where the } \\
\text { Process fluids are considered } \\
\text { nominally dry (i.e., no free water } \\
\text { present) Sour Service need not apply. }\end{array}$ & Original Req. & $\begin{array}{l}\text { Customer, } \\
\text { FDR }\end{array}$ & $\begin{array}{l}\text { The UCA have } \\
\text { identified the internals } \\
\text { of the AS Cooler could } \\
\text { be regarded as } \\
\text { nominally dry. } \\
\text { (additional analysis is } \\
\text { required) }\end{array}$ \\
\hline $\begin{array}{l}\text { The anti-surge cooler shall be } \\
\text { designed for full recycle flow at } \\
\text { compressor surge control line and at } \\
\text { compressor maximum continuous } \\
\text { speed }(105 \%) \text {. The outlet } \\
\text { temperature of compressor is allowed } \\
\text { to rise to the maximum operating } \\
\text { temperature during this operation. }\end{array}$ & Original Req. & $\begin{array}{l}\text { Customer, } \\
\text { FDR }\end{array}$ & $\begin{array}{l}\text { Dimensioning Case. } \\
\text { Accounted for in sizing } \\
\text { of design concepts. }\end{array}$ \\
\hline $\begin{array}{l}\text { The design must be checked for } \\
\text { maximum seabed current in order to } \\
\text { ensure that no hydrate formation can } \\
\text { occur during operation especially } \\
\text { during turn-down. }\end{array}$ & Original Req. & $\begin{array}{l}\text { Customer, } \\
\text { FDR }\end{array}$ & $\begin{array}{l}\text { Detailed Verification. } \\
\text { Not accounted for in } \\
\text { this research. } \\
\text { (Favors larger Cooler } \\
\text { tubes) }\end{array}$ \\
\hline
\end{tabular}




\begin{tabular}{|c|c|c|c|}
\hline Requirement & Classification & Source & Handling Method \\
\hline $\begin{array}{l}\text { An allowance will be made for a } \\
\text { buildup of calcium carbonate due to } \\
\text { the effect of the CP system. }\end{array}$ & Original Req. & $\begin{array}{l}\text { Customer, } \\
\text { FDR }\end{array}$ & $\begin{array}{l}\text { Accounted for in } \\
\text { thermal modelling. } \\
100 \mu \mathrm{m} \text { of } \\
\text { conductivity } 2.5 \\
\mathrm{~W} / \mathrm{mK} .[15]\end{array}$ \\
\hline $\begin{array}{l}\text { Steady state operation, with } \\
\text { production according to design } \\
\text { premise, shall not require MEG } \\
\text { injection to protect the cooler against } \\
\text { hydrates. }\end{array}$ & Original Req. & $\begin{array}{l}\text { Customer, } \\
\text { FDR }\end{array}$ & Favors larger tubes \\
\hline $\begin{array}{l}\text { The cooler shall be sized for } 0 \mathrm{~m} / \mathrm{s} \\
\text { seawater current. }\end{array}$ & Original Req. & $\begin{array}{l}\text { Customer, } \\
\text { FDR }\end{array}$ & $\begin{array}{l}\text { Included in Thermal } \\
\text { Modelling and sizing } \\
\text { of design concepts. }\end{array}$ \\
\hline $\begin{array}{l}\text { The AS Cooler Shall be designed } \\
\text { with min. } 0.5^{\circ} \text { Slope for water } \\
\text { drainage. }\end{array}$ & Original Req. & $\begin{array}{l}\text { Customer, } \\
\text { FDR }\end{array}$ & $\begin{array}{l}2^{\circ} \text { Slope used in } \\
\text { calculation and design. }\end{array}$ \\
\hline $\begin{array}{l}\text { To ascertain quality and safety The } \\
\text { Coolers Manufacturing Method and } \\
\text { the design concept shall properly } \\
\text { mitigate risk of HISC (Hydrogen } \\
\text { Induced Stress Cracking). }\end{array}$ & Derived Info. & Internal 1 & $\begin{array}{l}\text { If HISC Susceptible } \\
\text { materials are applied - } \\
\text { the headers will be } \\
\text { manufactured by HIP. }\end{array}$ \\
\hline $\begin{array}{l}\text { Larger Inner Diameters mitigate } \\
\text { clogging of tubes due to hydrates. }\end{array}$ & Derived Info. & Internal 2 & $\begin{array}{l}\text { Considered in Concept } \\
\text { Evaluation }\end{array}$ \\
\hline $\begin{array}{l}\text { The Cooler Shall fit the Process } \\
\text { module. }\end{array}$ & Derived Req. & Internal 2 & $\begin{array}{l}\text { All concepts have } \\
\text { considered constraints } \\
\text { of the process module. }\end{array}$ \\
\hline $\begin{array}{l}\text { The max. Number of standard AKSO } \\
\text { large Anodes fitted on the AS Cooler } \\
\text { unit is } 54\end{array}$ & Derived Req. & Internal 1 & $\begin{array}{l}\text { Considered in Concept } \\
\text { Evaluation }\end{array}$ \\
\hline $\begin{array}{l}\text { The weight of tubes and anodes shall } \\
\text { not exceed } 50 \text { tonnes. }\end{array}$ & Derived Req. & Internal 2 & $\begin{array}{l}\text { All concepts are } \\
\text { screened for weight } \\
\text { limits. }\end{array}$ \\
\hline $\begin{array}{l}\text { The Cooler may be designed of CS as } \\
\text { long as sufficient corrosion } \\
\text { allowance is proven and accepted by } \\
\text { Customer. }\end{array}$ & Derived Req. & $\begin{array}{l}\text { Internal } 2 \\
\text { Internal } 1\end{array}$ & $\begin{array}{l}\text { Considered in Concept } \\
\text { Evaluation - AHP }\end{array}$ \\
\hline $\begin{array}{l}\text { Uncoated Cooler shall be alloyed } \\
\text { with seawater resistant alloys. }\end{array}$ & Derived Req. & Internal 1 & $\begin{array}{l}\text { Considered in Concept } \\
\text { Evaluation }\end{array}$ \\
\hline $\begin{array}{l}\text { The Material Selection for the Cooler } \\
\text { shall be uniform. Meaning; Header } \\
\text { and tubes shall be of the same alloy } \\
\text { and grade. }\end{array}$ & Derived Req. & Internal 1 & $\begin{array}{l}\text { Considered in Concept } \\
\text { Evaluation }\end{array}$ \\
\hline
\end{tabular}




\begin{tabular}{|l|l|l|l|}
\hline Requirement & Classification & Source & Handling Method \\
\hline $\begin{array}{l}\text { The design Concepts shall measure } \\
\text { of performance shall be based on the } \\
\text { following CTQs: }\end{array}$ & Derived Req. & Internal 2 & $\begin{array}{l}\text { Considered in Concept } \\
\text { Evaluation. }\end{array}$ \\
- Maximize Constructability & & \\
- Minimize Cost & & & \\
- Maximize Robustness & & & \\
- Minimize Risk & & & \\
\hline
\end{tabular}

Table 2: Abbreviations

\begin{tabular}{|l|l|}
\hline Abbreviation & Definition \\
\hline Anodic C. & Anodic Coating \\
\hline An & Anode \\
\hline CP & Cathodic Protection \\
\hline Calc. & Calcareous \\
\hline Corr. & Corrosion \\
\hline H/M CRA & High/Medium Corrosion Resistant Alloy \\
\hline HIP & Hot Isostatic Pressing (Manufacturing Method) \\
\hline ID & Inner Diameter \\
\hline LAS & Low Alloy Steel \\
\hline S/M/L & Small / Medium / Large \\
\hline T/M/H W & Thin/Medium/Heavy Wall Thickness \\
\hline TQP & Technology Qualification Program \\
\hline
\end{tabular}




\section{Appendix B - Thermal Modelling}
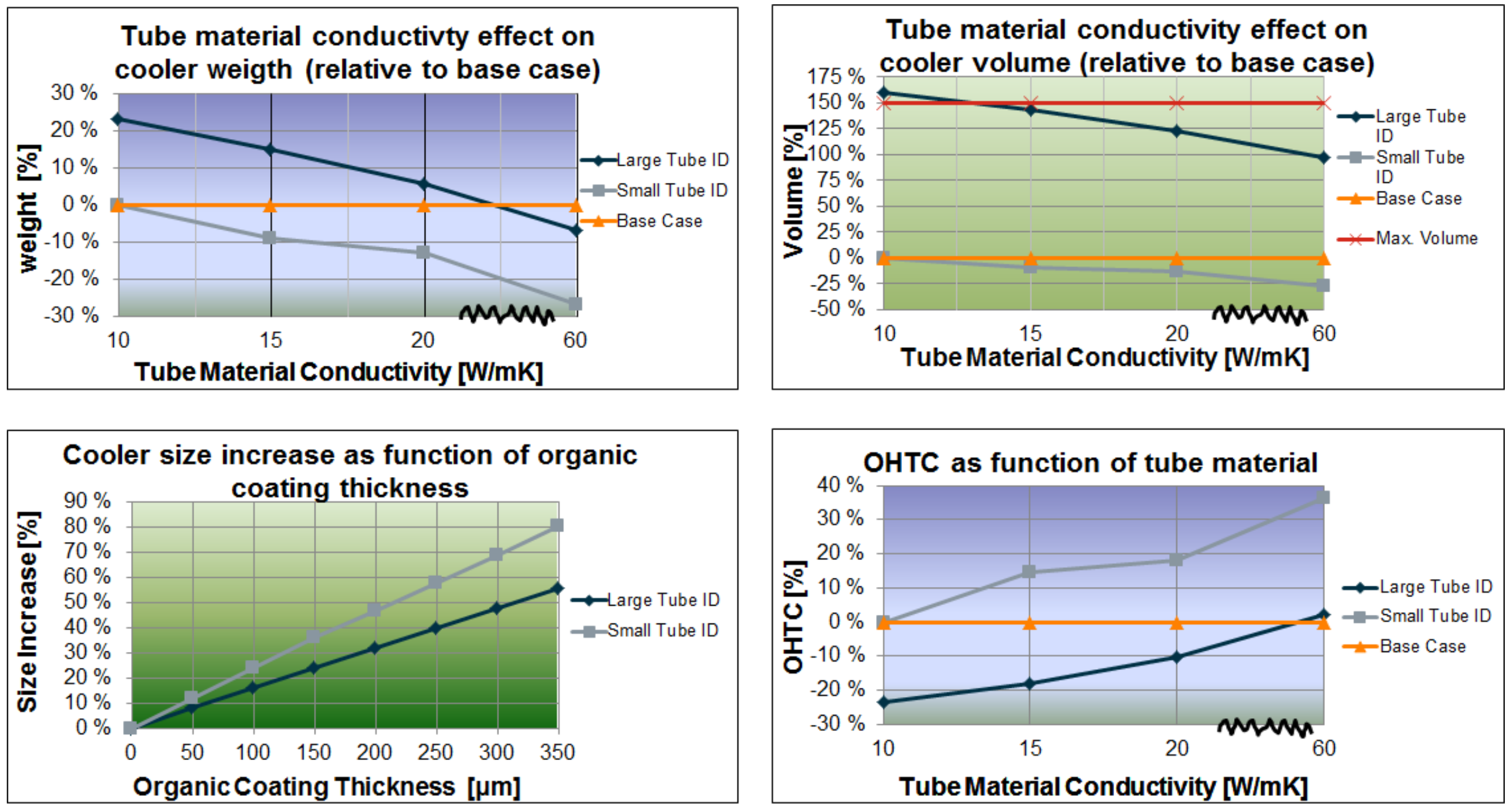